\title{
The correction of TEOM PM 10 measurements at different monitoring sites and climates
}

\author{
Jana Faganeli Pucer ${ }^{1}$ \\ (C) Springer Nature Switzerland AG 2019
}

\begin{abstract}
The reference method for $\mathrm{PM}_{10}$ and $\mathrm{PM}_{2.5}$ measurement in Europe is active sampling with subsequent gravimetric analysis. Also tapered element oscillating microbalance (TEOM) monitors are widely used across Europe for the assessment of particulate matter (PM), even though they are known to be biased due to the loss of semi-volatile materials attributed to sample heating. In our work we correct TEOM PM 10 measurements at eight different monitoring sites located in different surroundings and different climates across Slovenia to replicate reference measurements. We use simultaneous reference and TEOM measurements from a period of seven years (2011-2017) and assess the advantage of custom defined correction factors (with linear and orthogonal regression) compared to default correction factors. We further try to improve the corrections by adding meteorological parameters as inputs and training a linear model (lasso) and nonlinear model (random forest). Random forest and lasso models also enable us to evaluate the impact of different meteorological parameters or chemical compounds on TEOM measurements. Our results show that TEOM measurements can be efficiently corrected using correction factors defined with two linear regressions (for summer and winter) at most locations across continental Slovenia. Koper, which lies at the sea side, was the most problematic measurement site. There the measurements were the most affected by the meteorological situation, and they could not be successfully corrected. When examining the effect of the chemical composition at two different locations, levels of $\mathrm{NH}_{4}^{+}, \mathrm{NO}_{3}^{-}$, and organic carbon exhibited major impact on the discrepancies between reference and TEOM measurements.
\end{abstract}

Keywords $\mathrm{PM}_{10} \cdot$ Reference measurements $\cdot \mathrm{TEOM} \cdot$ Meteorological parameters · Chemical composition · Statistical models

\section{Introduction}

Inhalation of elevated levels of particulate matter (PM) suspended in the air can cause severe adverse health effects especially to the most vulnerable part of the population, to children, the elderly, and people with pre-existing medical conditions [33]. This is why most countries worldwide have created legislation that addresses PM levels. The acceptable levels of $\mathrm{PM}_{10}$ and $\mathrm{PM}_{2.5}$ in Europe are defined in Directive 2008/50/EC of the European Parliament [8].

$\mathrm{PM}_{10}$ is composed of particles that have an aerodynamic diameter ${ }^{1}$ equal or less than $10 \mu \mathrm{m}$, while $\mathrm{PM}_{2.5}$ is a subset of $\mathrm{PM}_{10}$ and comprise particles that have a aerodynamic diameter equal or less than $2.5 \mu \mathrm{m}$. There are two limit values set for $\mathrm{PM}_{10}$ and one for $\mathrm{PM}_{2.5}$ in EC [8]. The Directive states that in the European Union $\mathrm{PM}_{10}$ daily levels should

\footnotetext{
1 The aerodynamic diameter of a irregular particle is defined as that of a sphere whose density is $1 \mathrm{~g} / \mathrm{cm}^{3}$ (water) and settles in still air at the same velocity as the irregular particle [19].
}

Electronic supplementary material The online version of this article (https://doi.org/10.1007/s42452-019-1262-1) contains supplementary material, which is available to authorised users.

Jana Faganeli Pucer, jana.faganeli@fri.uni-lj.si | ${ }^{1}$ Večna pot 113, Ljubljana, Slovenia.

SN Applied Sciences (2019) 1:1235 | https://doi.org/10.1007/s42452-019-1262-1

Received: 1 July 2019 / Accepted: 10 September 2019 / Published online: 18 September 2019 
not exceed $50 \mu \mathrm{g} / \mathrm{m}^{3}$ more than 35 times per year and the annual average should be below $40 \mu \mathrm{g} / \mathrm{m}^{3}$. Yearly levels of $\mathrm{PM}_{2.5}$ should stay below $25 \mu \mathrm{g} / \mathrm{m}^{3}\left(20 \mu \mathrm{g} / \mathrm{m}^{3}\right.$ since 2020$)$.

The EU Directive also dictates the reference methods for assessment of air pollutant levels. The reference method for the assessment of both $\mathrm{PM}_{10}$ and $\mathrm{PM}_{2.5}$ is active sampling with subsequent gravimetric analysis [8]. Member states can also use several automatic measurement methods such as tapered element oscillating microbalance (TEOM) or beta-attenuation detectors. TEOM monitors are one of the most popular automatic PM measurement devices with 564 TEOMs used in 2017 for compliance assessment across Europe [10] also betaattenuation monitors are widely used $[7,10]$. There were 247 standard TEOMs and 317 TEOM with filter dynamics measurement system (FDMS) monitors. Slovenia used TEOMs for the assessment of $\mathrm{PM}_{10}$ levels between 2002 and 2011 (or 2012), when it switched everywhere to the reference assessment method (gravimetric), but left the TEOMs running for real-time assessment of hourly and daily $\mathrm{PM}_{10}$ levels to facilitate the forecasting of the exceedance of the daily limit value. The institution responsible for all PM measurements and assessment in Slovenia is the Slovenian Environment Agency (ARSO).

TEOM measurements are not equivalent to the gravimetric method due to the loss of semi-volatile material [4, $14,15,18]$ while the downside of the gravimetric method is the delay between sampling and gravimetric assessment done in the chemical analytical laboratory. ARSO usually collects gravimetric samples at sampling points every two weeks, and the samples are then analysed [13]. The gravimetric method is also biased as it can exhibit loss of semivolatile material during sampling, sample transportation and analysis [32] (the filers are conditioned at $20^{\circ} \mathrm{C}$ and 45-50\% relative air humidity) even though the procedure prescribed in the CEN EN 12341 standard is designed to minimise the loss of semi-volatile compounds. Gravimetric samples can also retain water which is dependant on their chemical composition; inorganic compounds are more hygroscopic than organic compounds [29, 30, 32]. The filters can also absorb water [29]. Despite the gravimetric method has its downsides, it is still the reference method in Europe and its results are valid for the assessment of the attainment with air quality standards by the European Commission [8]. As according to the EU legislation all other $\mathrm{PM}_{10}$ and $\mathrm{PM}_{2.5}$ measurement methods have to be calibrated to be equivalent to the gravimetric method we will regard its measurements as the ground truth.

The performance of TEOM measurements has been debated since their introduction in the 1990s. They are known to be biased when there is a large share of semi-volatile compounds in PM $[4,14,15,18]$. European countries that use TEOMs for the assessment of the compliance with air quality standards have to define correction factors and prove that the corrected TEOM measurements are equivalent to reference measurements at the investigated locations as described in "The European Guide to the demonstration of equivalence of ambient air monitoring methods" [9]. Most studies comparing TEOM to gravimetric measurements highlighted the impact of temperature on the discrepancy between TEOM and reference measurements $[4,14,18,28]$. TEOMs underestimate PM levels especially when levels are high $[2,4,18]$. Green et al. [15] proposed the use of a FDMS purge for measuring the loss of semi-volatile material and then use the defined correction factor at different sites across England. Hauck et al. [18] proposed a correction factor for loss of semi-volatile material and further correction for temperature; similarly Charron et al. [4] proposed further correction for temperature and humidity. Green and Fuller [14] proposed the correction for temperature and pressure. TEOM-FDMS monitors showed less discrepancies when compared to reference measurements than standard TEOMs, but Salvador and Chou [26] showed that they still underestimate semi-volatile compound levels. Charron et al. [4] suggested that strong day-to-day variations of the difference between TEOM and reference measurements attributed to the different share of semi-volatile compounds lead to difficulties in establishing corrections of TEOM measurements.

The consistency of automatic measurement methods with the reference method is rarely discussed in papers dealing with $\mathrm{PM}_{10}$ or $\mathrm{PM}_{2.5}$ levels, despite automatic methods are known to exhibit different performance compared to the reference method when PM has diverse chemical composition. In this paper we show that TEOM monitors' performance varies at different monitoring locations. Our paper is also a case study on how and when to use different statistical methods for the correction and assessment of automatic measurements. We also present an approach for the assessment of the influence of meteorological parameters and chemical composition on the performance of automatic measurements.

To show that the discrepancies between TEOM and reference measurements depend on the location, climate, and measurement date, we analyse TEOM measurements from Slovenia between 2011 and 2017 and compare them to reference measurements. Slovenia is a small country but it exhibits several different climates that can affect the composition of PM. The environment around the measurement site also affects $\mathrm{PM}_{10}$ composition, so we analyse measurements at diverse monitoring sites (urban, suburban, rural). We propose, compare, and discuss different statistical and data-mining methods and different input parameters (meteorological parameters) for the correction 
Fig. 1 The locations of the examined measurement sites (left) and the availability of different measurements (right). The map was composed with the help of the R package ggmap (Kahle and Wickham [21])

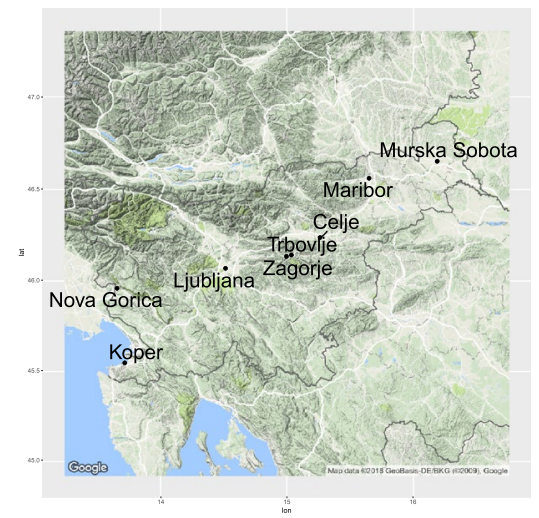

\begin{tabular}{cccccc} 
& & $\mathrm{PM}_{10}$ & & $\mathrm{PM}_{2.5}$ & Meteo \\
\hline Station/ & Reference & $\begin{array}{c}\text { reg. } \\
\text { TEOM }\end{array}$ & $\begin{array}{c}\text { TEOM- } \\
\text { FDMS }\end{array}$ & Reference & \\
\hline Ljubljana & $\checkmark$ & $\checkmark$ & & & $\checkmark$ \\
Celje & $\checkmark$ & $\checkmark$ & & & $\checkmark$ \\
Zagorje & $\checkmark$ & $\checkmark$ & & & $\checkmark$ \\
Trbovlje & $\checkmark$ & $\checkmark$ & & & $\checkmark$ \\
Maribor & $\checkmark$ & & $\checkmark$ & $\checkmark$ & $\checkmark$ \\
Murska Sobota & $\checkmark$ & $\checkmark$ & & & $\checkmark$ \\
Nova Gorica & $\checkmark$ & & $\checkmark$ & & $\checkmark$ \\
Koper & $\checkmark$ & $\checkmark$ & & & $\checkmark$ \\
Ljubljana BF & & & & $\checkmark$ & \\
\hline
\end{tabular}

of TEOM measurements. The study is focused on the discrepancies between standard TEOM or TEOM-FDMS measurements and reference measurements when measuring $\mathrm{PM}_{10}$. As the European legislature is more focused on $\mathrm{PM}_{10}$ than on $\mathrm{PM}_{2.5}$ automatic measurements of $\mathrm{PM}_{2.5}$ are not performed in Slovenia.

The remainder of the paper is organised as follows: in Sect. 2 we present the investigated locations and the used data, we also present the employed methods in the statistical analysis. In Sect. 3 we present and discuss the results of the correction of TEOM measurements, which models are useful in which instances, and the most important meteorological parameters and chemical components affecting the discrepancies between the two measurement methods. With Sect. 4 we conclude the paper.

\section{Methods}

In this section we present the measurement locations where reference and TEOM measurements were performed simultaneously. We present the $\mathrm{PM}_{10}$ measurements, measurements of meteorological parameters and measurements of the chemical compositions of $\mathrm{PM}_{2.5}$. We also introduce the different models used for the correction of TEOM measurements and the evaluation methods.

\subsection{Measurement locations}

ARSO measures $\mathrm{PM}_{10}$ levels with TEOMs and gravimetric samplers simultaneously at eight different locations across Slovenia. The monitoring sites Ljubljana, Celje, Trbovlje and Zagorje are located in basins of central Slovenia, Murska Sobota is located in the Pannonian plane, while Maribor is located in north-eastern Slovenia on open terrain (see Fig. 1 left). All these monitoring sites are located in the part of Slovenia with continental climate. Nova Gorica and Koper are located in the region with Mediterranean climate (south-west). Koper is located at the seaside, while Nova Gorica is further away from the sea. All the monitoring sites are classified according to the EU legislation [8]. Most monitoring sites are urban background, Trbovlje and Zagorje are urban traffic monitoring sites, Trbovlje is a suburban background monitoring site, while Murska Sobota is a rural background monitoring site.

The Slovenian continental climate is characterised by cold winters with frequent temperature inversions, hot summers, abundant precipitations and low wind conditions (especially in winter). In Mediterranean Slovenia the climate is moderated by the Mediterranean sea. Winter temperatures are not as low as in continental Slovenia (rarely below freezing), summers and springs are warm and there is much more wind as in the continental part. These conditions affect PM levels, especially the frequent temperature inversions in winter.

\subsection{PM measurements}

TEOMs are based on a small vibrating glass tube whose oscillation frequency changes when aerosol particles are deposited on it. The monitors are known to be quite robust, but their downside is the loss of semi-volatile material attributed to the heating of the sample $\left(50^{\circ} \mathrm{C}\right)$ $[1,2,16,28]$ or $\left.35^{\circ} \mathrm{C}\right)[1,2,16]$. Ayers et al. [2] and Green et al. [15] report greater loss of semi-volatile material at $50^{\circ} \mathrm{C}$ than at $35^{\circ} \mathrm{C}$. The TEOM-FDMS monitors are based on the same measurement principle, but are also equipped with FDMS and are designed to be able to measure the semi-volatile fraction of airborne particulate matter. TEOMFDMS measurement systems are popular across Europe. In England they showed a superior performance compared to standard TEOMs. They passed the equivalence test while TEOM monitors failed $[15,17]$.

The "Guidance to member states on $\mathrm{PM}_{10}$ monitoring and inter-comparisons with the reference method" [31] recommends that winter levels measured with standard TEOMs $\left(50^{\circ} \mathrm{C}\right.$ heating) should be multiplied by 1.3 (default correction factor) to account for the loss of semi-volatile materials. "The European Guide to the demonstration 
Fig. 2 Medians of the yearly mean levels for the period 2011-2017 with the maximal and minimal recorded yearly levels (left) and median of yearly exceedances in the same period with the minimal and maximal recorded yearly exceedance (right) for all measurement sites
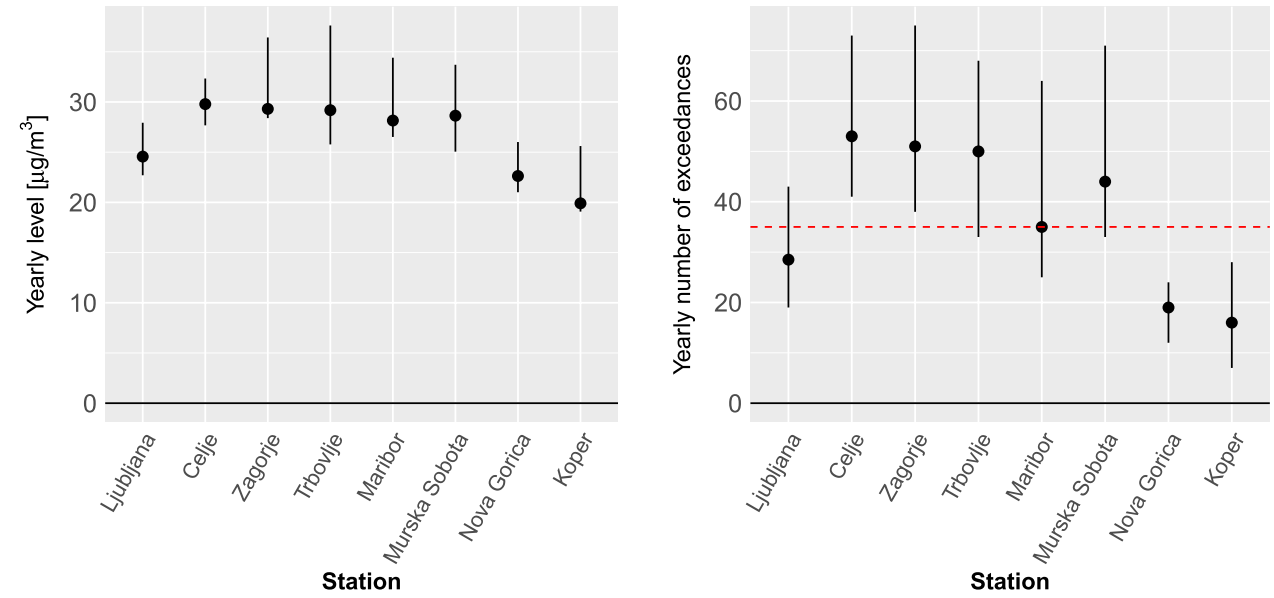

of equivalence of ambient air monitoring methods" [9] advises users to assess individual correction factors for each measurement location. It does not advise to define corrections for TEOM-FDMS monitors.

In Slovenia TEOM monitors are used at all monitoring sites except in Maribor and Nova Gorica, where standard TEOMs were replaced with TEOM-FDMS monitors in 2008 and 2009, respectively (see Fig. 1). The standard TEOMs heat PM samples at $50^{\circ} \mathrm{C}$. We analysed $\mathrm{PM}_{10}$ levels (TEOM measurements) as daily aggregated values. For active sampling of $\mathrm{PM}_{10}$ Sven Leckel SEQ 47/50 instruments are used everywhere. The $\mathrm{PM}_{10}$ levels are than assessed gravimetrically in the chemical analytical laboratory. $\mathrm{PM}_{2.5}$ is also sampled with Sven Leckel SEQ 47/50 instruments which are standard reference samplers according to CEN EN 12341 for $\mathrm{PM}_{10}$ and $\mathrm{PM}_{2.5}$. Sven Leckel SEQ 47/50 instruments are low volume samplers and $47 \mathrm{~mm}$ filters are used. At the Maribor and Ljubljana Biotechical Faculty_Ljubljana BF (monitoring locations where chemical analysis of samples is performed) quartz filters are used, while at other locations PM is sampled on glass filters. All filters are pre-fired. The sampling period is from midnight to midnight ( $24 \mathrm{~h}$ ). The samplers have cooled inlet systems by sheath air and covered sampled filters within the magazine to prevent losses of particulate volatile material. During transportation filters are kept in a cooled container to further prevent volatilisation. Field blanks are used to check the procedure. All measurements are performed according to the EN 12341:2014 standard [11].

In the chemical analytical laboratory filters are conditioned at $20+/-1^{\circ} \mathrm{C}$ and $45-50 \%$ relative air humidity for $48 \mathrm{~h}$ prior their deployment to the measurement site. After collection the filters are again conditioned at the same temperature and air humidity for at least 48 hours before weighing (Mettler Toledo XPE 206 DR/M micro balance, sensitivity $1 \mu \mathrm{g}$ ). The evaluated expanded relative uncertainty of the gravimetric method (including bias, repeatability, reproducibility, mass uncertainty, air flow uncertainty, sampling uncertainty, weighing uncertainty) was estimated to be $13 \%$.

The investigated period is between 2011 and the end of 2017. The levels measured in the months January, February, March, October, November, and December are regarded as winter measurements, while those measured in April, May, June, July, August, and September are regarded as summer measurements.

Figure 2 left shows the yearly mean levels for individual stations. Monitoring sites located in the continental part of Slovenia exhibited much higher levels than monitoring sites located in the Mediterranean climate (Koper and Nova Gorica). All yearly levels at all monitoring sites were below the yearly limit value. In Fig. 2 the number of yearly exceedances is shown. Koper and Nova Gorica never exceeded (in the observed period) the recommended number of 35 exceedances, while the number was exceeded each year in Celje and Zagorje. In Trbovlje and Murska Sobota it was exceeded almost all years. High levels of $\mathrm{PM}_{10}$ in basins of continental Slovenia are common in winter, while the levels in summer are generally low.

Figure 3 shows the relationships between reference and TEOM measurements. If the measurements were equivalent, the points would lie on the straight line $(y=x)$. TEOM measurements underestimate reference measurements especially in winter, while TEOM-FDMS measurements mostly overestimate summer levels.

\subsection{Meteorological parameters}

To analyse the effect of meteorological parameters on the discrepancies between TEOM and reference measurements we observe the effect of different meteorological parameters: the temperature measured at $2 \mathrm{~m}$, 


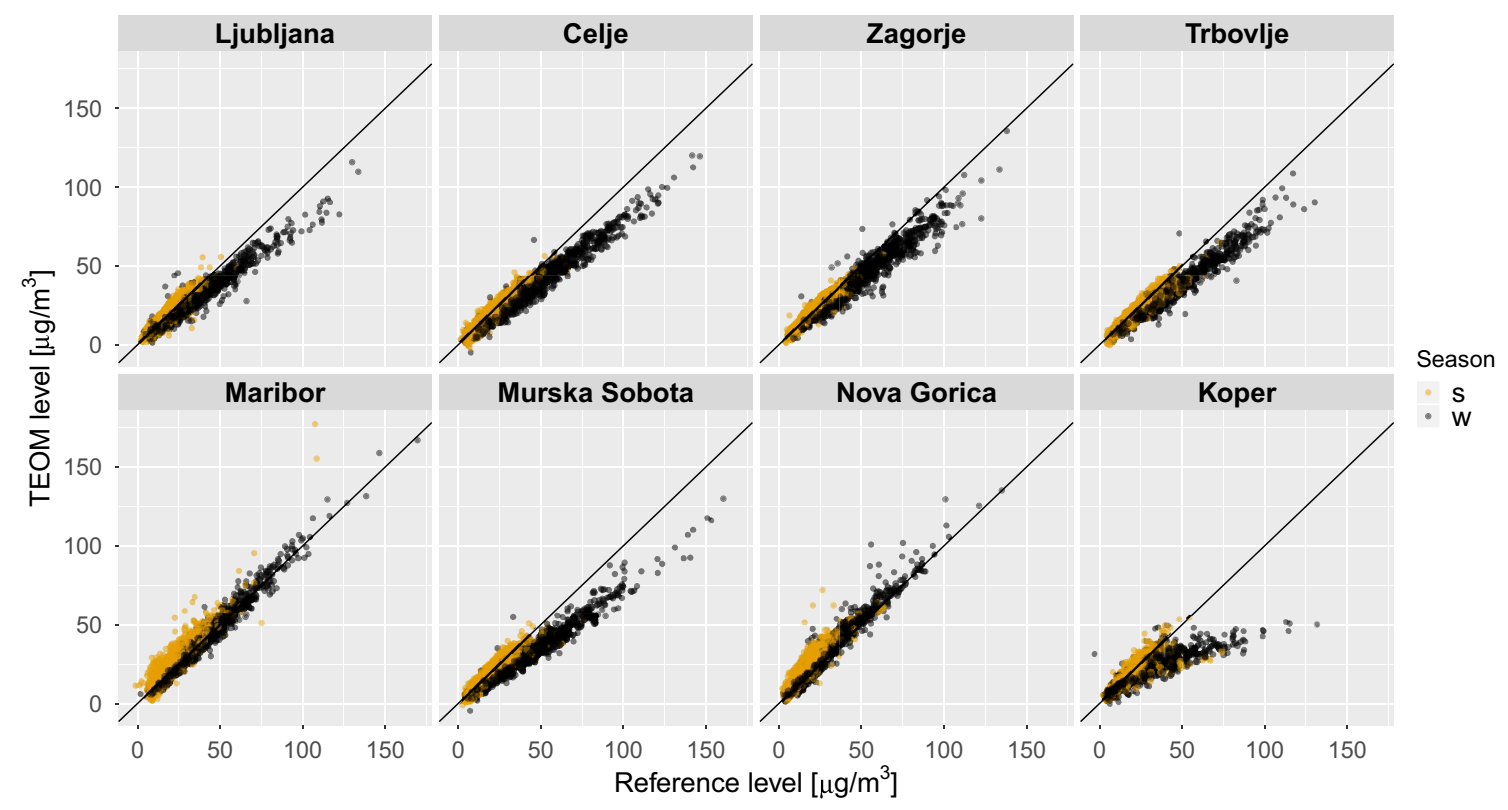

Fig. 3 The relationship of reference versus TEOM measurements at different measurement sites. Summer values are depicted in yellow while winter in grey

air humidity, air pressure, wind speed and gust at $10 \mathrm{~m}$, and global solar radiation. All parameters were measured alongside $\mathrm{PM}_{10}$ automatic and gravimetric measurements. In our analysis we use the daily mean, maximal and minimal value of all available meteorological parameters, for each day the $\mathrm{PM}_{10}$ measurements are compared.

\subsection{Chemical composition of $\mathrm{PM}_{10}$}

The most common chemical compounds lost due to standard TEOM heating of sampled PM are ammonium nitrate $\left(\mathrm{NH}_{4} \mathrm{NO}_{3}\right)[4,14,15,18]$ and semi-volatile organic compounds $[20,28]$. To determine which chemical compounds present in $\mathrm{PM}_{10}$ affect the discrepancy between TEOM and reference measurements we analysed levels of different ions $\left(\mathrm{Ca}^{2+}, \mathrm{Cl}^{-}, \mathrm{K}^{+}, \mathrm{Mg}^{2+}, \mathrm{Na}^{+}, \mathrm{NH}_{4}^{+}, \mathrm{NO}_{3}^{-}, \mathrm{SO}_{4}^{2-}\right)$ and organic carbon (Corg). For the assessment of ion concentrations the chemical analytical laboratory at ARSO performs ion chromatography [25], while organic carbon is analysed using thermal-optical carbon analysis [25]. All analyses are performed according to the EU legislation.

During thermal-optical carbon analysis samples are heated at increasing temperatures (according to the EUSAAR 2 protocol [25]) first in a reduced atmosphere (He) where carbonates and some organics (up to $30 \%$ ) decompose. The organic decomposition is continuously monitored by laser transmission through the sample matrix. The produced $\mathrm{CO}_{2}$ is catalitically reduced to $\mathrm{CH}_{4}$ and detected by flame ionisation detector (FID). Subsequently, the analyser turns to oxic atmosphere $(\mathrm{He}+5 \%$
$\mathrm{CH}_{4}$ ) and organic and elemental $\mathrm{C}$ is oxidised to $\mathrm{CO}_{2}$ and catalitically reduced to $\mathrm{CH}_{4}$ and detected by FID. Thermaloptical carbon analysis is performed according to the CEN/ TR 16243 standard.

lon chromatography (or ion exchange chromatography) allows the separation of ions and polar molecules based on their affinity to the ion exchanger [22]. lon chromatography utilises a liquid mobile phase, a separation column and a detector to measure the species eluted from the column. There are two types of ion exchange chromatography, cation exchange and anion exchange chromatography. For anion analysis ARSO uses Dionex DX - 120 with while for cation analysis a Shimadzu LC-10 ion chromatograph. Anions are analysed according to the ISO 10304-1 standard, and cations are analysed according to the ISO 14911 standard. The guidance for anion and cation analysis in PM $_{2.5}$ is PD CEN/TR 16269:2011.

lons and organic carbon were analysed according to the EU legislation [8] in $\mathrm{PM}_{2.5}$ samples every second day. Unfortunately, ARSO does no chemical analysis of $\mathrm{PM}_{10}$ samples (only for measurement campaigns). $\mathrm{As}_{4} \mathrm{NH}_{3}^{+}, \mathrm{NO}_{3}^{-}$, and $\mathrm{SO}_{4}^{2-}$ are predominantly found in finer particles $\left(\mathrm{PM}_{2.5}\right)$ [1], we hypothesise that their level is mostly equal in both fractions $\left(\mathrm{PM}_{10}\right.$ and $\left.\mathrm{PM}_{2.5}\right)$. While $\mathrm{Ca}^{2+}, \mathrm{Cl}^{-}, \mathrm{K}^{+}, \mathrm{Mg}^{2+}, \mathrm{Na}^{+}$come usually from sea spray or soil resuspension and are more abundant in the coarse fraction [5]. To check this claim we compared levels of $\mathrm{NH}_{4}^{+}, \mathrm{NO}_{3}^{-}, \mathrm{Mg}^{2+}, \mathrm{Na}^{+}, \mathrm{Ca}^{2+}$ and organic carbon (that stood out later in the analysis see Sect. 3.3) that were measured simultaneously for one year at the Maribor measurement site (see Fig. 1 of Online resource 1). Levels 


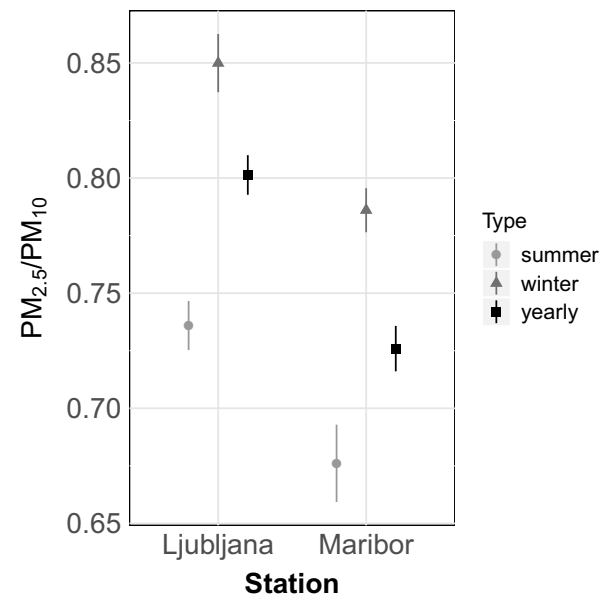

Fig. 4 The median $\mathrm{PM}_{2.5} / \mathrm{PM}_{10}$ relationship $\left(\mathrm{PM}_{2.5}\right.$ level dived by the $\mathrm{PM}_{10}$ level) with two standard errors on different time intervals for Maribor and Ljubljana BF measurement sites (summer-summer measurements, winter-winter measurements, year-all measurements)

of $\mathrm{NH}_{4}^{+}, \mathrm{NO}_{3}^{-}$, and organic carbon were mostly equivalent in both fractions while ion levels were much lower in $\mathrm{PM}_{2.5}$ than in $\mathrm{PM}_{10}$. Still the levels of ions in both fractions were highly correlated (see Fig. 1 of Online resource 1).

In Maribor all analysed compounds were sampled in $\mathrm{PM}_{2.5}$ at the exact location as $\mathrm{PM}_{10}$. In Ljubljana the analysed $\mathrm{PM}_{2.5}$ was sampled 4 kilometers away from $\mathrm{PM}_{10}$ sampling (Ljubljana BF monitoring site). Figure 4 shows the relationship of $\mathrm{PM}_{2.5}$ and $\mathrm{PM}_{10}$ at the two investigated monitoring sites. The relationship is calculated as the daily level of $\mathrm{PM}_{2.5}$ divided by the daily level of $\mathrm{PM}_{10}$ measured at the same location at the same time. The share of $\mathrm{PM}_{2.5}$ in $\mathrm{PM}_{10}$ is large especially in winter when the main source of PM is indoor heating [13].

\subsection{Correction of TEOM PM 10 measurements}

As gravimetric measurements are regarded as reference values, our goal was to correct TEOM measurements so they could resemble gravimetric measurements as close as possible. In our work we show different statistical methods to relate TEOM and gravimetric measurements. We compare them to uncorrected TEOM measurements and corrected with the default correction factors:

Default correction factors Winter TEOM levels were multiplied by 1.3. Summer levels were not corrected (for summer and winter months see Sect. 2.2). TEOM-FDMS measurements were not corrected.

Linear regression was fitted to relate TEOM levels to reference levels. One regression line was defined for winter and one for summer levels.
Orthogonal regression [6] is similar to linear regression but instead of minimising the vertical distance between points and the fitted line (in the reference measurement vs. TEOM measurement plane), it minimises the perpendicular distance. This is the method proposed in EC Working Group [9]. We fitted one line for summer and one for winter.

As we also wanted to assess the impact of meteorological parameters on TEOM measurements, we added the parameters described in Sect. 2.3 to our regression. After adding the meteorological parameters the number of input parameters is quite large, which can lead to over-fitting when fitting a linear or orthogonal regression model. We hypothesised that not all meteorological parameters affect TEOM measurements, so we employed methods that incorporate parameter selection simultaneous to fitting the models:

Lasso is the L1-regularised regression. As lasso discards the non-important parameters, it enables us to assess which parameters affect TEOM measurements. We used the lasso implementation from $R$ package glmnet [12]. We estimated the optimal value of the regularisation parameter using tenfold cross-validation.

Random forest [3] (RF) is a nonlinear model. We used it to assess if there was a nonlinear relationship between input parameters (TEOM measurements and meteorological measurements) and reference measurements. We used the $\mathrm{R}$ package randomForest [23]. We set the number of trees to 1000 .

When predicting $\mathrm{PM}_{10}$ levels with lasso and random forest (RF) we did not split the dataset in winter and summer data, but used modelled seasonality with sine (sinDOY) and cosine (cosDOY) functions of day of the year.

To resemble a real-life setting we evaluated the models using a time-respecting rolling window approach. Initially, we fitted the model on data prior 2014 and evaluated it on 2014 data. Each year was then added to the initial data (training data) and the models were fit again. The process was repeated until data of all years were used to get predictions for the 2014-2017 period. The predictions were evaluated in terms of mean absolute error (MAE) between the reference measurements and modelled values. We also compared the number of exceedances of the daily limit value for $\mathrm{PM}_{10}$. All evaluations were performed on independent data (as described above).

We assessed the importance of different meteorological parameters affecting the discrepancies between reference and TEOM measurements by observing the standardised lasso coefficients and the importance coefficients of the 


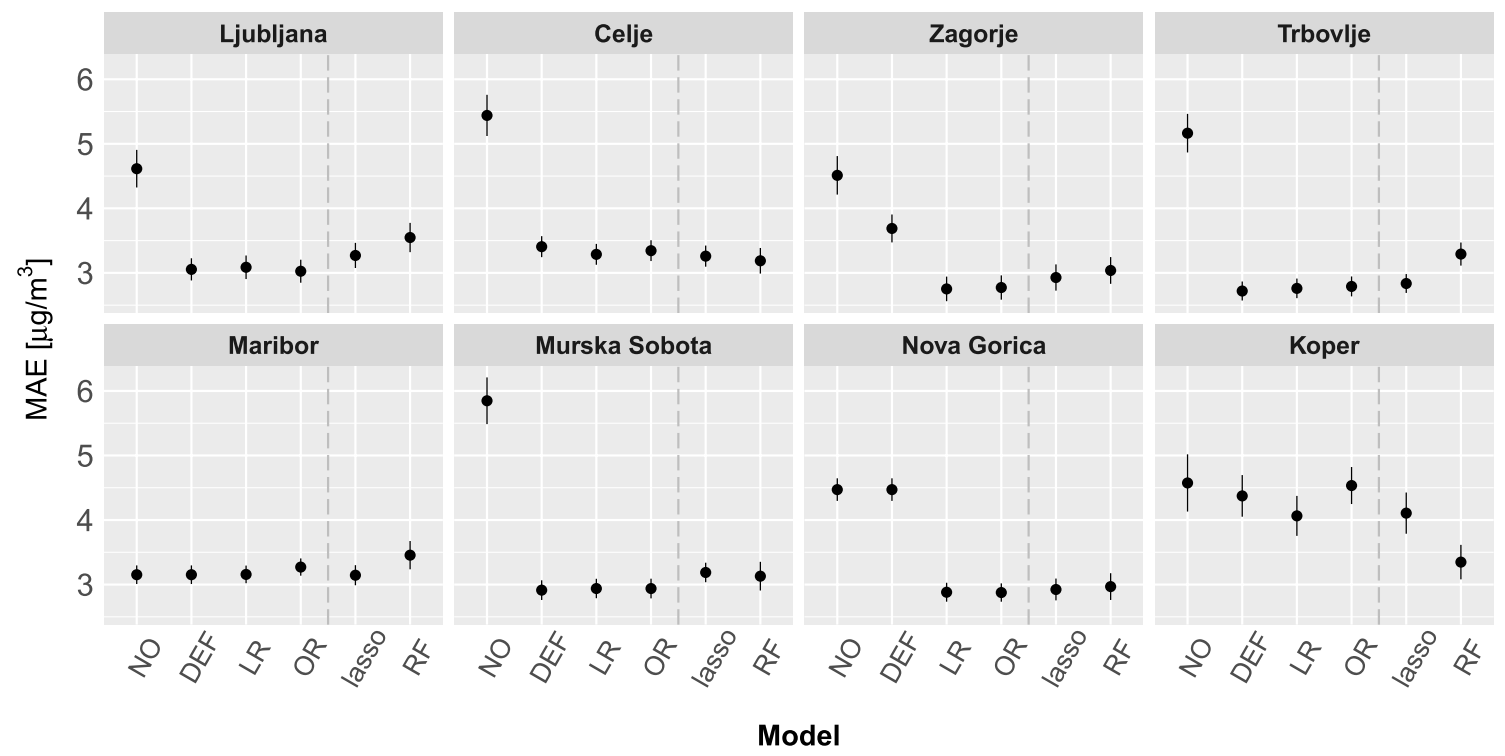

Fig. 5 MAE and two standard errors for different corrections and different measurement locations. The dashed vertical line delimit the simple corrections (NO-raw TEOM values, DEF default, $L R$ linear

RF model for each monitoring site. Only the coefficients different from zero were taken into account.

\section{Results and discussion}

In this section we present and discuss the performance of different models used for the correction of TEOM PM 10 measurements and discuss their applicability at different monitoring sites. We also analyse the effect of different meteorological parameters (see Sect. 3.2) and the chemical composition (see Sect. 3.3).

\subsection{Correction of TEOM measurements}

Mean absolute error (MAE) with two standard errors are shown in Fig. 5 while Fig. 6 shows the median, minimal and maximal percentage of wrongly detected exceedances per year for each monitoring site in the investigated period. The exhibited MAE for uncorrected TEOM measurements (see Fig. 5) is much higher than for all applied corrections, except in Maribor and Nova Gorica where it is actually the same as the default correction (TEOM-FDMS needs no correction). The performance of the default correction is comparable to the performance of both evaluated corrections (linear and orthogonal regression) in Celje, Ljubljana, Maribor, Murska Sobota and Trbovlje in terms of MAE. In Zagorje and Nova Gorica both evaluated linear and orthogonal corrections outperform the default correction (in terms of MAE). regression, $O R$ orthogonal regression) from the corrections that use more input parameters and more complicated models (lasso-L1 regularized regression, $R F$ random forest)

The estimated number of exceedances also improves when corrections are applied (see Fig. 6). When we evaluate the concordance of the number of exceedances of the daily LV at the investigated monitoring sites in Trbovlje and Murska Sobota, the default correction factor and corrections with linear and orthogonal regression perform equivalently. In Ljubljana and Maribor the default correction seems to outperform all others. In Celje, Nova Gorica and Zagorje both corrections outperform the default correction which gives an overestimation of exceedances.

When comparing linear to orthogonal regression (the method recommended in EC Working Group [9]), there is no clear advantage in using orthogonal regression over ordinary linear regression in terms of MAE. In some instances (Ljubljana and Koper) it slightly better estimates the number of exceedances than linear regression.

When we correct for the effects of the meteorological situation (see Fig. 5), we gain the most in Celje and Koper. In Koper MAE decreases substantially when meteorological parameters are taken into account. In Celje the decrease in MAE is not so obvious, but when we examine the number of detected exceedances, the spread of the discrepancy of detected exceedances becomes much smaller when meteorological parameters are included (RF). Koper seems to be a very problematic measurement location where levels (especially the exceedances of the daily LV) are largely underestimated even after correction (see the exceedance discrepancy in Fig. 6). TEOM measurements underestimate high levels in Koper the most (see Fig. 3), when compared to other measurement locations. 


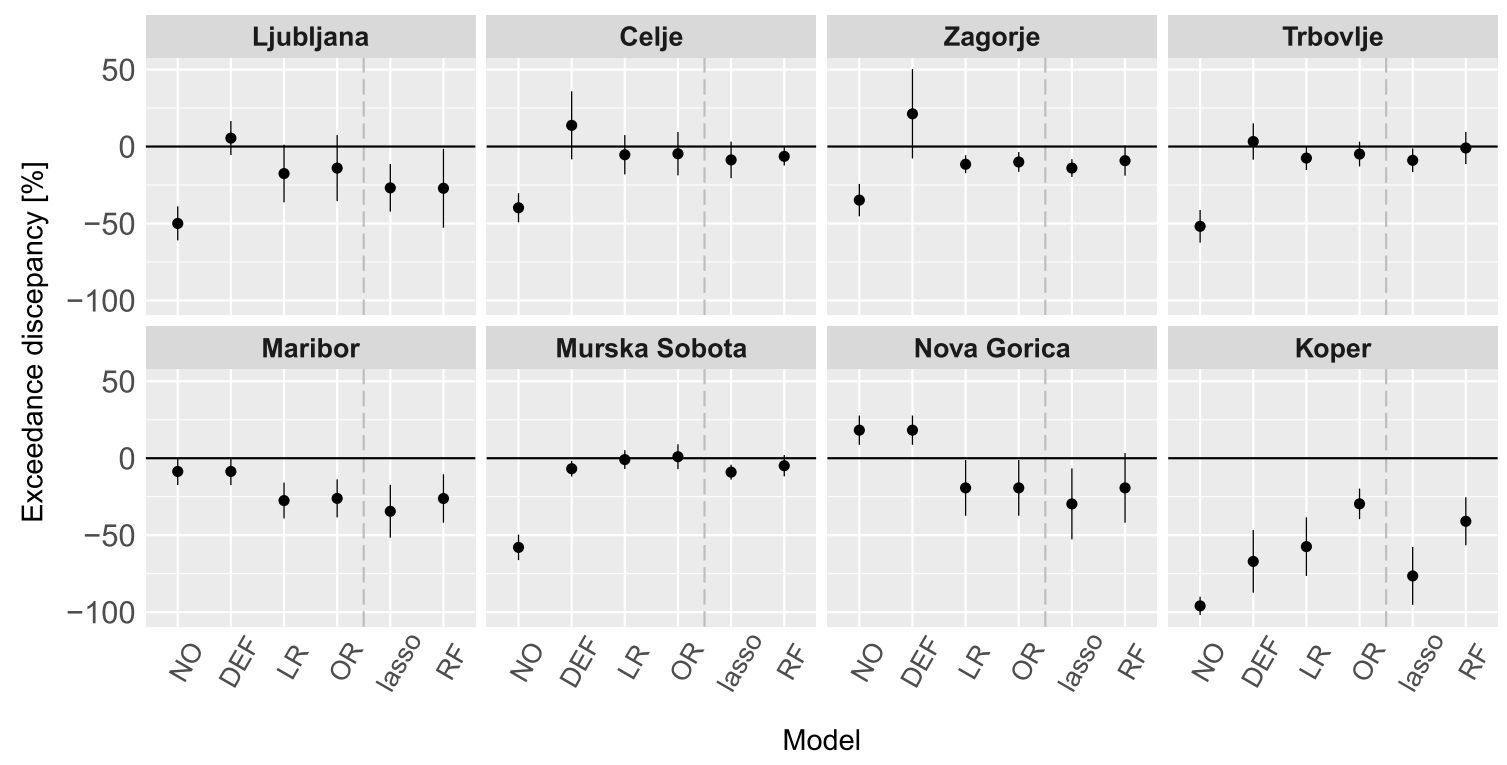

Fig. 6 Median difference of determined yearly exceedances with TEOM and reference $\mathrm{PM}_{10}$ measurements in percents with the minimal and maximal estimated value in the observed period. Minus sign [\%] indicates underestimation and plus overestimation. The dashed vertical line delimit the simple corrections (NO-raw TEOM

Koper in general exhibits lower $\mathrm{PM}_{10}$ levels and fewer exceedances of the daily LV than the rest of Slovenia.

There have been some major changes around the Ljubljana monitoring site (construction and enlargement of the parking lot), maybe the under-performance of TEOM in Ljubljana could be attributed to this fact. This is also evident in Fig. 2 of Online resource 1 -in Ljubljana there is more variation in winter correction factors between years than at other measurement locations (except Koper). Koper monitoring site is located at the seaside, only a few hundred metres from the sea, and a few kilometres from the Italian border. lons coming from sea spray could have contributed to a higher content of water in PM [29, 30, 32] measured by the reference method. Major effect of meteorological parameters at this location supports this hypothesis (connection with $\mathrm{RH}$ ). Another hypothesis is that as Koper lies right on the border with Italy, it is influenced by trans-boundary PM. In north-eastern Italy there is extensive agriculture that increases the share of ammonium nitrate in PM. As there was no chemical analysis of PM in Koper available, we were not able to confirm or reject these hypotheses. Koper TEOM was calibrated several times during our observation period, and there were no anomalies reported.

The correction factors defined with linear regression are listed in Table 1 of the "Appendix". TEOM measurements are higher than reference measurements in summer everywhere, this is especially evident in Ljubljana (for standard values, $D E F$ default, $L R$ linear regression, $O R$ orthogonal regression) from the corrections that use more input parameters and more complicated models (lasso-L1 regularized regression, RF random forest)

TEOMs) and in Maribor and Nova Gorica (TEOM-FDMS). Standard TEOM measurements underestimate winter levels everywhere while TEOM-FDMS overestimate winter levels too. The largest underestimation could be observed in winter in Koper (slope of 1.6), with a large negative intercept $\left(-6 \mu \mathrm{g} / \mathrm{m}^{3}\right)$. In Koper also the value of $R^{2}$ of the regression model (winter) is the lowest, supporting our thesis, that there are some sporadic sources of $\mathrm{PM}_{10}$ that are not detected by TEOMs especially in winter. This could also be a result of water retention by $\mathrm{PM}_{10}$ rich with inorganic salts from sea spray or water retained by gravimetric filters.

As we used the rolling window approach (see Sect. 2.5) the corrections varied from year to year. Figure. 2 of Online Resource 1 shows how the correction coefficients (slopes) of the linear regressions changed when different data were used (one year was added each time the correction was calculated.) The greatest coefficient variation was observed in Koper in winter. An increase in slope could also be observed in Ljubljana in winter. Figures 3 and 4 of Online Resource 1 show the relationship of reference measurements and corrected TEOM measurements when using two regression lines and the lasso regression which includes the sine and cosine functions of day of the year in the regression. There seems to be no clear advantage in using lasso over two regression lines at most measurement locations (see Online Resource 1 Fig. 3 and 4). 
Fig. 7 The estimated effect of different meteorological parameters affecting the discrepancies between reference and TEOM measurements as evaluated by lasso. Darker fields are more important

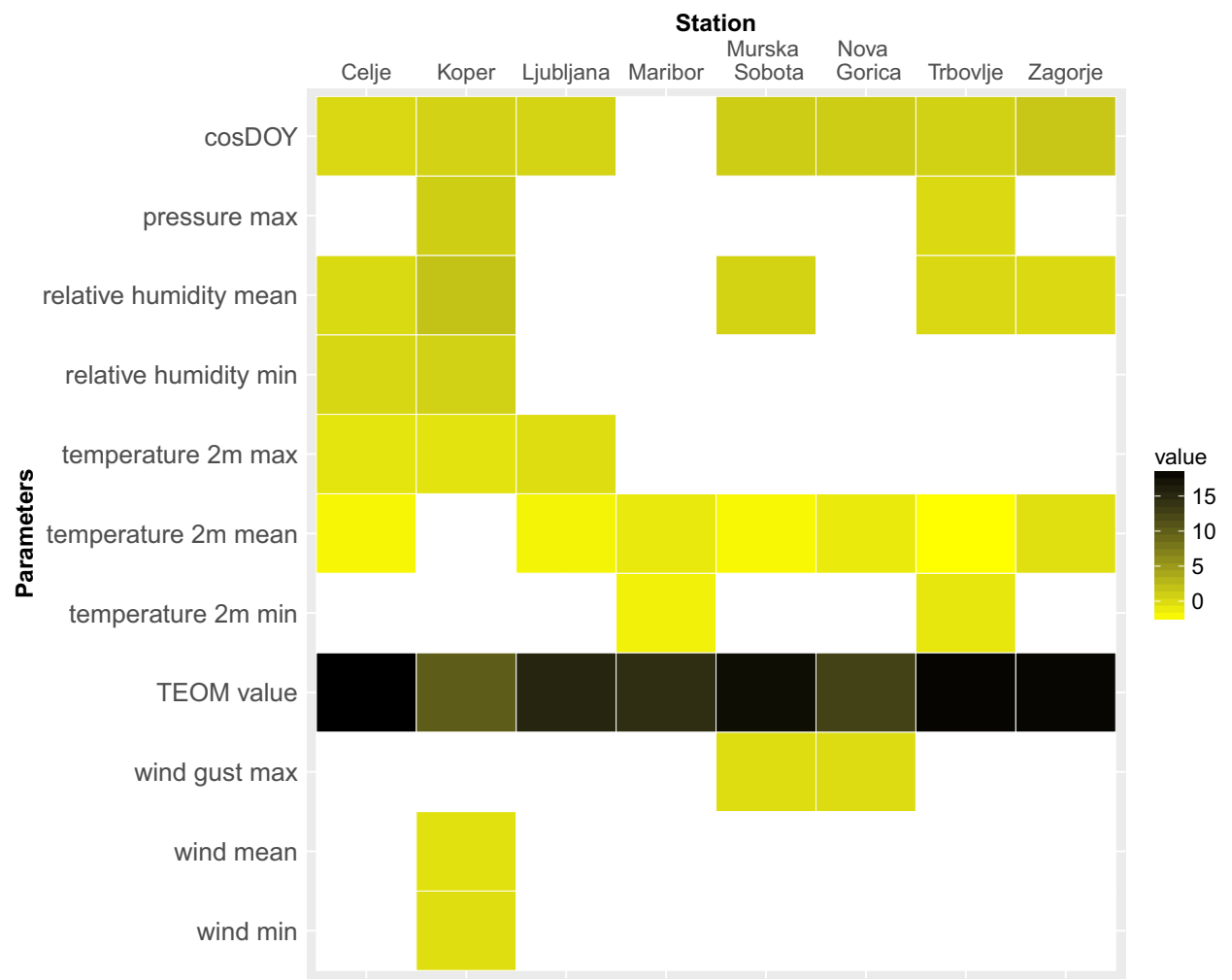

\subsection{Influence of meteorological parameters}

We also analysed the influence of meteorological parameters on the discrepancies between reference and automatic measurements at different locations (see Fig. 7) by observing lasso coefficients of the input parameters. In this case all data were used as training data. At all locations reference measurements are strongly related to TEOM measurement. Results (see Fig. 7) show that when modelling reference measurements the value of TEOM measurements is the least important in Koper, Nova Gorica, and Maribor. This finding is in line with the correction results (see Fig. 5). Adding meteorological parameters improves the corrections in Maribor, Koper, Nova Gorica, and Celje. Apart from the TEOM values, seasonality, and temperature also played an important role in the regression at most locations, supporting the hypothesis that the composition of PM is related to temperature (e.g. in winter there are emissions from indoor heating). TEOM measurements are also affected by air humidity at some locations. There was no effect of air humidity observed in Maribor and Nova Gorica, where TEOM-FDMS monitors are used. The impact of air humidity and wind is the largest in Koper. Wind affects TEOM measurements also in Murska Sobota and Nova Gorica. Sharratt and $\mathrm{Pi}$ [27] in a controlled experiment (wind tunnel) observed that TEOMs measure higher levels than active samplers when wind speed is high. Even though in Maribor $\mathrm{PM}_{10}$ is measured with TEOM-FDMS, temperature exhibits a major effect when compared to reference measurements. Wind conditions are different at different measurement sites; there is more wind in the Mediterranean part of Slovenia (Koper and Nova Gorica) and in the eastern part of Slovenia (Murska Sobota). At those locations the wind can also transport PM. Both Koper and Nova Gorica lie on the border with heavily industrialised norther Italy so the wind can carry pollutants to these locations. The measurement station Murska Sobota lies near a settlement that uses wood for indoor heating. In Murska Sobota there are known incidences of high $\mathrm{PM}_{10}$ levels measured when the wind blows directly from the settlement direction. Those are probably the reasons why the wind plays a major role at those locations.

When we analysed the TEOM measurements from Koper we discovered that there were some days when air humidity was very high and there were extreme discrepancies between TEOM and reference measurements. This could be due to the hygroscopicity of inorganic compounds in PM which are likely to retain water. As standard TEOMs heat PM samples water evaporates. The best performing model in Koper was RF which indicates that there are some nonlinear relationships between meteorological parameters and discrepancies between TEOM and reference measurements. 


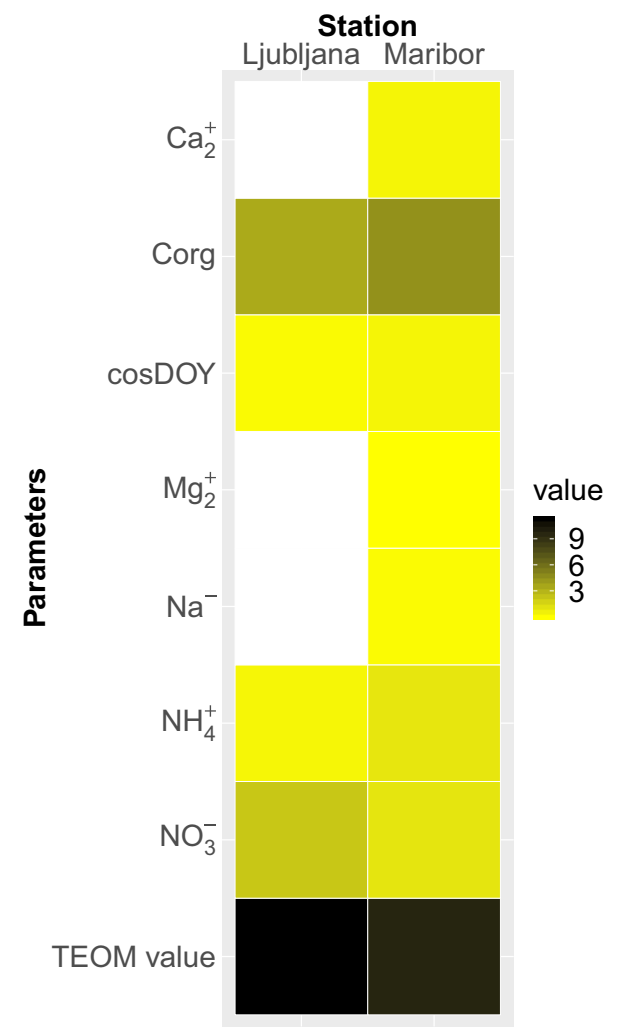

Fig. 8 Estimated chemical compounds affecting the discrepancies between TEOM and reference measurements as evaluated by lasso. Darker fields are more important

\subsection{Effect of $\mathrm{PM}_{10}$ chemical composition}

We also analysed the effect of the chemical composition of $\mathrm{PM}_{10}$ on the discrepancies between reference and TEOM measurements. We used the same technique described in Sect. 2.5. We evaluated the importance of different chemical compounds by fitting a lasso model and observing the evaluated standardised lasso coefficients. The input parameters to the model were the TEOM measurements, sine and cosine functions of day of the year to describe seasonality, and the chemical compounds described in Sect. 2.4.

The results of the effect of the chemical composition of PM are shown in Fig. 8. The level of organic carbon plays an important role in the discrepancies between reference and TEOM measurements, when either standard TEOM or TEOM-FDMS monitors are used. This is typical in winter when levels of organic carbon in PM are high, especially due to domestic heating and traffic [13]. This finding is in line with the research described in Tortajada-Genaro and Borrás [28]. Tortajada-Genaro and Borrás [28] advise that the correction of standard TEOM measurements should be made not with a predefined correction factor, but based on organic carbon content.
As expected, the amount of both $\mathrm{NH}_{4}^{+}$and $\mathrm{NO}_{3}^{-}$in $\mathrm{PM}$ affects TEOM measurements in Ljubljana where standard TEOMs (with heating) are used. The main source of $\mathrm{NH}_{4}^{+}$is agriculture, while $\mathrm{NO}_{3}^{-}$is emitted mostly from traffic and indoor heating. Surprisingly even when using TEOM-FDMS in Maribor, which should not be affected by loss of semivolatile compounds, $\mathrm{NH}_{4}^{+}$and $\mathrm{NO}_{3}^{-}$content affect the discrepancy between measurements. Salvador and Chou [26] states that FDMS corrections are not enough to correct for the entire loss of semi-volatile compounds. Contrary this discrepancy could also be due to the loss of semi-volatile compounds by the reference method [32]. TEOM measurements in Maribor are also affected by levels of calcium $\left(\mathrm{Ca}^{2+}\right)$, magnesium $\left(\mathrm{Mg}^{2+}\right)$ and sodium $\left(\mathrm{Na}^{+}\right)$in $\mathrm{PM}$. Higher concentrations of these ions are probably a result of winter sanding and salting of roads. The Maribor monitoring site is located on a sidewalk right next to a road. Figure 1 of Online Resource 1 shows higher sodium levels in winter at the Maribor monitoring site. Calcium and magnesium are also present in the soil and their PM levels probably depend on soil resuspension. The TEOM dependence on ion levels could explain the Koper situation, where we can observe great discrepancies between reference and TEOM measurements in some instances. In Koper there are elevated concentrations of ions in the air from sea spray. In the sea water there are high levels of $\mathrm{Na}^{+}, \mathrm{Mg}^{2+}, \mathrm{Ca}^{2+}, \mathrm{SO}_{4}^{2-}$ and $\mathrm{HCO}_{3}^{-}$[24]. The Koper monitoring site is located a few 100 metres from the sea.

\section{Conclusions}

Our results show that by estimating two correction lines (slope and intercept), one for summer and one for winter, from historical data and applying on independent test data, we are able to get reliable corrections at most measurement location across continental Slovenia. This indicates that the relationship between reference and TEOM measurements is linear at most locations. This is in line with Hauck et al. [18] where successful corrections could be determined for TEOM measurements in central Europe. The TEOM corrections we determined outperformed or performed equivalently to the default corrections at the vast majority of measurement sites. Overall the inclusion of meteorological parameters did not improve the correction of TEOM measurements at most sites.

TEOM measurements were the most biased (compared to the reference) in Koper, especially when we compare the number of estimated exceedances of the daily LV with the reference number of exceedances. TEOM measurements considerably underestimated high $\mathrm{PM}_{10}$ levels at this location. Koper is the only investigated location, where meteorology exhibited important influence on TEOM measurements. 
In Koper RF outperformed lasso which indicates that there is a nonlinear relation between some meteorological parameters and PM levels in Koper. The RF correction still cannot explain the large underestimation that could be observed in some instances. The great discrepancy could be explained with water retention by inorganic salts present in PM or by the gravimetric filter. Koper is the only investigated measurement location from the Slovene seaside, so the influence of the ions from sea water in the air could have played an important role. The sporadic influence of long-range transport of pollutants from Italy can also affect Koper levels.

TEOM-FDMS were less sensitive to air humidity than standard TEOMs which heat the sampled PM (see Fig. 7). Both TEOM-FDMS measurements, from Maribor and Nova Gorica showed that when uncorrected they overestimate $\mathrm{PM}_{10}$ levels in summer and winter. The over-estimations are more evident in summer. This could also be attributed to the loss of semi-volatile material by the reference method which is consistent with Zhu et al. [34]. The discrepany between TEOM-FDMS measurements and the reference method depend on temperature (see Fig. 7) and organic carbon content (see Fig. 8).
Acknowledgements The author would like to thank the department of Air quality of the Slovenian Environment Agency (ARSO) who provided PM levels and meteorological data. Special thanks go to Tanja Koleša from ARSO who helped explain the procedures done in their chemical analytical laboratory. The work is the result of a long and fruitful collaboration between the Faculty of Computer and Information Science and ARSO.

\section{Compliance with ethical standards}

Conflict of interest The author declare no conflict of interest.

\section{Appendix}

Table 1 shows the calculated correction lines for all measurement sites for summer (S) and winter (W). All slopes are significant for summer and winter data. Figure 9 shows the importance of meteorological parameters as evaluated by the RF model. RF does not eliminate any parameter but shrinks its importance.
Table 1 The correction coefficients calculated with the sliding window, the first correction coefficients were calculated for the period before 2014 then one year was added at a time (sliding window) and the coefficients were recalculated

\begin{tabular}{|c|c|c|c|c|c|c|}
\hline Station & Summer(S)/ & $\begin{array}{l}\text { Slope } \\
\text { Winter(W) }\end{array}$ & Slope & $\begin{array}{l}\text { Intercept } \\
p \text { value }\end{array}$ & Intercept & $\begin{array}{l}\mathrm{R}^{2} \\
p \text { value }\end{array}$ \\
\hline \multirow[t]{2}{*}{ Ljubljana } & $S$ & 0.87 & 0.00 & 1.45 & 0.00 & 0.84 \\
\hline & W & 1.25 & 0.00 & -0.98 & 0.00 & 0.94 \\
\hline \multirow[t]{2}{*}{ Koper } & $S$ & 0.92 & 0.00 & 0.86 & 0.00 & 0.88 \\
\hline & W & 1.64 & 0.00 & -6.75 & 0.00 & 0.73 \\
\hline \multirow[t]{2}{*}{ Zagorje } & $S$ & 0.97 & 0.00 & -0.21 & 0.23 & 0.93 \\
\hline & W & 1.15 & 0.00 & 0.43 & 0.24 & 0.94 \\
\hline \multirow[t]{2}{*}{ Trbovlje } & $S$ & 0.99 & 0.00 & 0.52 & 0.01 & 0.90 \\
\hline & W & 1.25 & 0.00 & 0.83 & 0.01 & 0.94 \\
\hline \multirow[t]{2}{*}{ Celje } & $S$ & 0.91 & 0.00 & 1.64 & 0.00 & 0.89 \\
\hline & W & 1.24 & 0.00 & -0.02 & 0.94 & 0.95 \\
\hline \multirow[t]{2}{*}{ Murska Sobota } & $S$ & 0.93 & 0.00 & 0.95 & 0.00 & 0.88 \\
\hline & W & 1.34 & 0.00 & -0.16 & 0.61 & 0.95 \\
\hline \multirow[t]{2}{*}{ Maribor } & $S$ & 0.69 & 0.00 & 3.99 & 0.00 & 0.77 \\
\hline & W & 0.95 & 0.00 & 1.17 & 0.00 & 0.96 \\
\hline \multirow[t]{2}{*}{ Nova Gorica } & $S$ & 0.74 & 0.00 & -0.59 & 0.01 & 0.83 \\
\hline & W & 0.91 & 0.00 & -0.35 & 0.22 & 0.93 \\
\hline
\end{tabular}


Fig. 9 The estimated effect of different meteorological parameters affecting the discrepancies between reference and TEOM measurements as evaluated by RF. Darker fields are more important

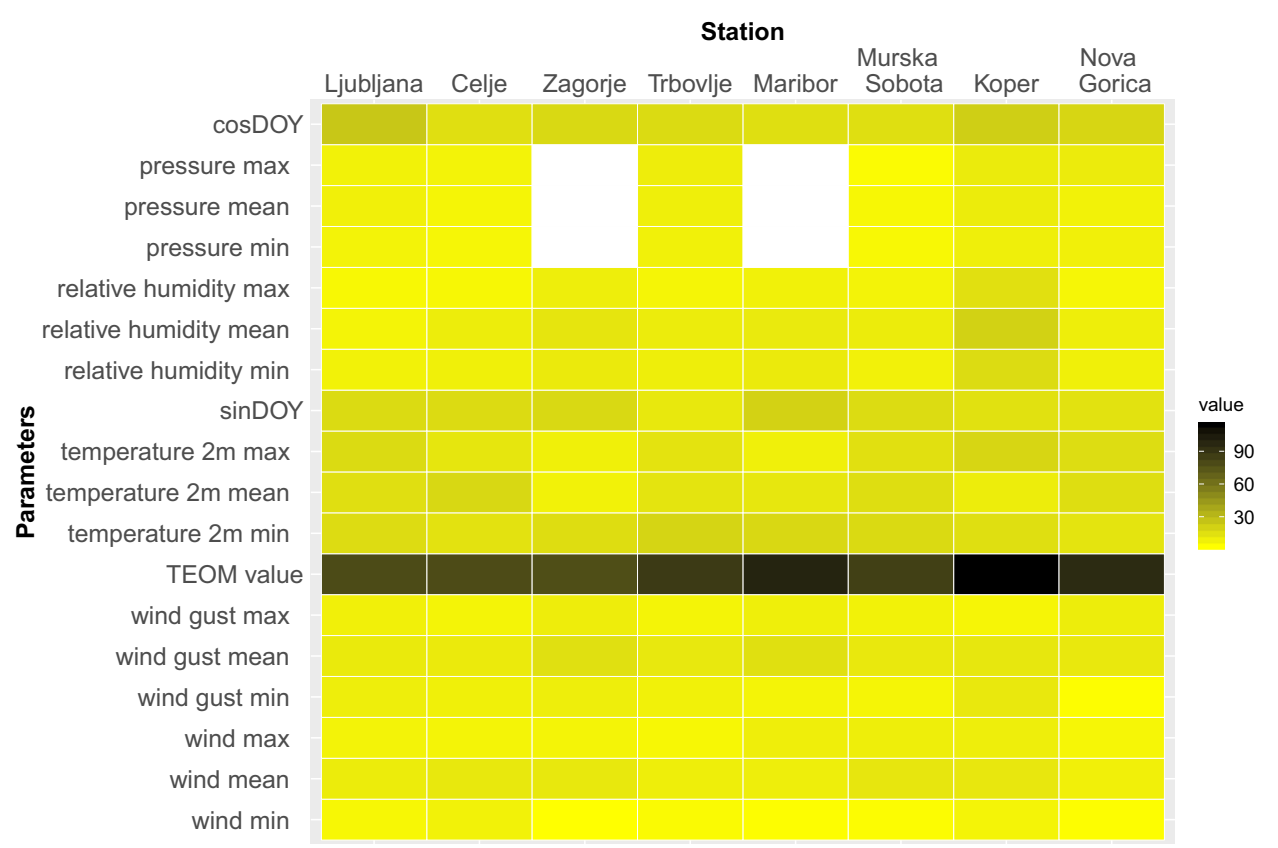

\section{References}

1. Allen $G$, Sioutas $C$, Koutrakis $P$, Reiss R, Lurmann FW, Roberts PT (1997) Evaluation of the TEOM method for measurement of ambient particulate mass in urban areas. J Air Waste Manag Assoc 47(6):682-689

2. Ayers GP, Keywood MD, Gras JL (1999) TEOM vs. manual gravimetric methods for determination of PM2.5 aerosol mass concentrations. Atmos Environ 33(22):3717-3721

3. Breiman $L$ (2001) Random forests. Mach Learn 45(1):5-32

4. Charron A, Harrison RM, Moorcroft S, Booker J (2004) Quantitative interpretation of divergence between PM10 and PM2. 5 mass measurement by TEOM and gravimetric (Partisol) instruments. Atmos Environ 38(3):415-423

5. Contini D, Cesari D, Genga A, Siciliano M, lelpo P, Guascito MR, Conte $M$ (2014) Source apportionment of size-segregated atmospheric particles based on the major water-soluble components in lecce (italy). Sci Total Environ 472:248-261

6. Deming WE (1943) Statistical adjustment of data. Wiley, Hoboken

7. Dinoi A, Donateo A, Belosi F, Conte M, Contini D (2017) Comparison of atmospheric particle concentration measurements using different optical detectors: potentiality and limits for air quality applications. Measurement 106:274-282

8. EC. Directive 2008/50/EC of the European Parliament and of the Council of 21 May 2008 on ambient air quality and cleaner air for Europe. Official Journal of the European Union, (2008)

9. EC Working Group (2010) Guide to the demonstration of equivalence of ambient air monitoring methods

10. EEA. Information on assessment methods used for Air Quality monitoring in the EU, 2017. URL http://aided.apps.eea. europa.eu/?source=\%7B\%22query\%22\%3A\%7B\%22 match_. all\%22\%3A\%7B\%7D\%7D\%2C\%22display_type\%22\%3A\%22tab ular\%22\%7D. Accessed 30 Sep 2018

11. EN UNI (2014) 12341: 2014. Air Quality-Determination of the PM10 fraction of suspended particulate matter. Reference method and field test procedure to demonstrate reference equivalence of measurements methods
12. Friedman J, Hastie T, Tibshirani R (2009) glmnet: Lasso and elastic-net regularized generalized linear models. $R$ package version 1(4)

13. Gjerek M, Koleša T, Logar M, Matavž L, Murovec M, Paradiž B, Rus M, Žabkar R(2016) Kakovost zraka v Sloveniji v letu 2016. Technical report, ARSO. URL http://www.arso.gov.si/zrak/kakovost\%20 zraka/poro\%C4\%8Dila\%20in\%20publikacije/Porocilo_2016.pdf

14. Green D, Fuller GW (2006) The implications of tapered element oscillating microbalance (TEOM) software configuration on particulate matter measurements in the UK and Europe. Atmos Environ 40(29):5608-5616

15. Green DC, Fuller GW, Baker T (2009) Development and validation of the volatile correction model for PM10-an empirical method for adjusting TEOM measurements for their loss of volatile particulate matter. Atmos Environ 43(13):2132-2141

16. Grover BD, Kleinman M, Eatough NL, Eatough DJ, Hopke PK, Long RW, Wilson WE, Meyer MB, Ambs JL (2005) Measurement of total PM2.5 mass (nonvolatile plus semivolatile) with the Filter Dynamic Measurement System tapered element oscillating microbalance monitor. J Geophys Res Atmos 110(D7)

17. Harrison D, Maggs R, Booker J (2006) UK equivalence programme for monitoring of particulate matter. Bureau Veritas Report No. Bureau Veritas/AQ/AD202209/DH, 2396

18. Hauck $H$, Berner $A$, Gomišček $B$, Stopper $S$, Puxbaum $H$, Kundi M, Preining O (2004) On the equivalence of gravimetric PM data with TEOM and beta-attenuation measurements. J Aerosol Sci 35(9):1135-1149

19. Hinds WC (1999) Aerosol technology: properties, behavior, and measurement of airborne particles. Wiley, Hoboken

20. Jaques PA, Ambs JL, Grant WL, Sioutas C (2004) Field evaluation of the differential TEOM monitor for continuous PM2. 5 mass concentrations special issue of aerosol science and technology on findings from the fine particulate matter supersites program. Aerosol Sci Technol 38(S1):49-59

21. Kahle D, Wickham H (2013) ggmap: spatial visualization with ggplot2. R J 5(1):144-161

22. Li D, Liu S (2019) Chapter 10—drinking water detection. In: Li $\mathrm{D}$, Liu $\mathrm{S}$ (eds) Water quality monitoring and management, pp 251-267. Academic Press 
23. Liaw A, Wiener M (2002) Classification and regression by randomforest. R News 2(3):18-22

24. Millero FJ (2016) Chemical oceanography. CRC Press, Boca Raton

25. Ruzer LS, Harley NH (2012) Aerosols handbook: measurement, dosimetry, and health effects. CRC press, Boca Raton

26. Salvador CM, Chou CC-K (2014) Analysis of semi-volatile materials (SVM) in fine particulate matter. Atmos Environ 95:288-295

27. Sharratt $\mathrm{B}, \mathrm{Pi} \mathrm{H}$ (2018) Field and laboratory comparison of PM10 instruments in high winds. Aeolian Res 32:42-52

28. Tortajada-Genaro L-A, Borrás E (2011) Temperature effect of tapered element oscillating microbalance (TEOM) system measuring semi-volatile organic particulate matter. J Environ Monit 13(4):1017-1026

29. Triantafyllou E, Diapouli E, Tsilibari EM, Adamopoulos AD, Biskos G, Eleftheriadis K (2016) Assessment of factors influencing PM mass concentration measured by gravimetric \& beta attenuation techniques at a suburban site. Atmos Environ 131:409-417

30. Van Dingenen $R$, Raes F, Putaud J-P, Baltensperger $U$, Charron A, Facchini M-C, Decesari S, Fuzzi S, Gehrig R, Hansson H-C et al (2004) A european aerosol phenomenology - 1: physical characteristics of particulate matter at kerbside, urban, rural and background sites in europe. Atmos Environ 38(16):2561-2577

31. Williams M, Bruckmann P (2002) Guidance to member states on pm10 monitoring and intercomparisons with the reference method. Final Report der EC Working Group on Particulate Matter

32. Wilson WE, Chow JC, Claiborn C, Fusheng W, Engelbrecht J, Watson JG (2002) Monitoring of particulate matter outdoors. Chemosphere 49(9):1009-1043

33. World Health Organization (January 2003) Health aspects of air pollution with particulate matter, ozone and nitrogen dioxide. Report on a WHO working group, Bonn, Germany 13-15:2003

34. Zhu K, Zhang J, Lioy PJ (2007) Evaluation and comparison of continuous fine particulate matter monitors for measurement of ambient aerosols. J Air Waste Manag Assoc 57(12):1499-1506

Publisher's Note Springer Nature remains neutral with regard to jurisdictional claims in published maps and institutional affiliations. 